\title{
PENSAR E FAZER CIÊNCIA: FILOSOFIA DA CIÊNCIA E PRAGMATISMO CLÁSSICO
}

\author{
Raquel Barbosa da Silva ${ }^{1}$
}

\begin{abstract}
RESUMO
O artigo pretende apontar o método pragmatista como instrumento útil na compreensão da prática científica, partindo do diálogo com os filósofos William James e Charles Sanders Peirce. Além disso, fará considerações gerais sobre a ciência e alguns dos critérios de demarcação que a diferem de outros conhecimentos. Por último, estabelecer- se-á um posicionamento sobre a natureza e o objetivo da ciência segundo a abordagem pragmatista.
\end{abstract}

Palavras-chave: Filosofia da Ciência, Pragmatismo, Epistemologia, Peirce, James.

\begin{abstract}
The paper aims to point out the pragmatist method as a useful tool for understanding the scientific practice, departing from the dialogue with the philosophers William James and Charles Sanders Peirce. Furthermore, it will make general considerations about science and some of the demarcation standards that distinguishes it from other knowledge. In conclusion, a position will be established on the nature and purpose of science according to the pragmatist approach.
\end{abstract}

Keywords: Philosophy of Science, Pragmatism, Epistemology, Peirce, James.

\footnotetext{
${ }^{1}$ Artigo escrito como trabalho final da disciplina Práticas em Ciências \& Humanidades na Universidade Federal do ABC, baseado em partes de um projeto de Iniciação Científica que atualmente se encontra em processo com financiamento da FAPESP, sob a orientação do professor Dr. Renato Kinouchi. Sobre a autora: Estudante do Bacharelado em Ciências \& Humanidades e do Bacharelado Filosofia na UFABC.
} 


\section{Introdução}

Muito se tem discutido sobre o que é ciência nos manuais de filosofia da ciência, ainda assim o imaginário social encontra-se povoado de falsas concepções, persistindo dificuldades em se tratar de ciência - às vezes até na universidade. De um lado, a ideia de que o cientista é um gênio que trabalha sozinho em seu laboratório a fim de descobrir coisas; de outro, a ideia de que a ciência nada mais é do que um discurso imbuído de autoridade, onde uma comunidade julga o que é certo ou errado baseada numa pretensa objetividade e num método infalível. Discutir-se-á ao longo do texto ambas as visões em busca de uma concepção mais precisa de ciência, em outras palavras, explicar aquilo que torna a ciência distinta do senso comum, útil e relevante para humanidade, sem, contudo, alçá-la a uma torre de marfim.

O propósito deste artigo é responder em que medida o pragmatismo clássico apresenta uma visão adequada sobre a ciência. Para tanto, apresenta-se algumas das particularidades do método pragmatista nas visões de Charles Sanders Peirce e William James, de modo a melhor compreender a ciência, visto que os fundadores deste movimento desenvolveram pensamentos afinados com o método científico e sua herança epistemológica ajuda a pensar sobre as fundamentações e diferenças entre crenças ${ }^{2}$. Cabe lembrar que ao pensar as diferenças entre ciência e não-ciência não se admite uma visão que anule o valor de crenças que não estão orientadas pelo método científico, mas busca-se um entendimento mais meticuloso da questão.

A ideia de que as crenças são todas sem fundamentos dissolve qualquer tentativa de demarcar o que é ciência e o que não é, o que constitui prejuízo ao entendimento. Com efeito, a ciência distingue-se de outras formas de conhecimento enquanto empreendimento cognitivo, pois explica a partir de um prognóstico que considera a generalidade não acidental, sendo que qualquer tentativa de isolar suas hipóteses reduz a força dos argumentos e "o conhecimento científico tem caráter essencialmente avaliada independentemente das demais" (CHIBENI, 2006, p. 9).

Neste sentido, o pensamento do médico, psicólogo e filósofo William James serve como fundamento para a discussão acerca do significado da verdade, bem como do lugar da

\footnotetext{
${ }^{2}$ Toma-se crença como uma disposição da mente, a convicção de que as coisas são de uma forma e não de outra, dito de outro modo, crenças são opiniões; sem elas não haveriam ações, pois segundo o pragmatismo ambas estão estritamente relacionadas: a crença é geradora de ação. Para C. S. Peirce existem vários métodos de fixação da crença, ou seja, formas de estabelecer a opinião, porém, o método científico é o único "método pelo qual nossas crenças possam ser causadas por algo em nada humano, mas por alguma permanência externa" (PEIRCE, 2008, p.53).
} 
ciência - do ponto de vista pragmatista. Ao escrever sobre o que consiste o pragmatismo ${ }^{3}$, James o caracteriza enquanto método e teoria geral do que significa a verdade. Enquanto que a formulação original do pragmatismo criada por Peirce ${ }^{4}$ entende a verdade como algo público, e o método científico como o único que apresenta alguma distinção entre um caminho certo e errado. Entende-se, aqui, que é preciso renunciar a uma concepção tradicional de ciência, como uma busca de conhecimento verdadeiro e universal.

O método pragmatista pode ser caracterizado como instrumento para determinação do significado das palavras e crenças mediante as consequências futuras, em outras palavras, consiste na avaliação de como a escolha de um conceito provoca ações. Entretanto, é preciso dizer que a formulação do pragmatismo de Peirce e James possui aproximações e distanciamentos, todavia, no que concerne a compreensão sobre a ciência e seu método “[p]ara ambos [...] o que há de distintivo, na ciência, é que ela promove um acordo intersubjetivo, por meio da expressão de leis que organizam as inúmeras sensações individuais" (KINOUCHI, 2007, p.219).

Ademais, procura-se fazer uso da herança do pragmatismo clássico sem, contudo, pretender abordar todas suas conclusões. A apreciação das teorias é. portanto, ferramenta (e não fim), e o posicionamento adotado ao final deste texto não necessariamente, diz respeito às formulações de Peirce e James, embora esteja imbuído de sua influência.

\section{O que torna a ciência diferente de outros conhecimentos?}

Rubem Alves defende que a ciência não constitui um novo conhecimento, mas, antes, caracteriza-se como senso comum disciplinado, especializado e imerso numa visão que possui profundidade. $\mathrm{O}$ autor apresenta a base compartilhada entre a ciência e o senso comum, que provém da necessidade de compreender o mundo e agir sobre ele (ALVES, 1981). Contudo, a afirmação da continuidade entre o bom senso e o conhecimento científico não revela as particularidades do pensamento científico por ele desenvolvido durante a obra. Se há uma continuidade entre o senso comum e a ciência, as diferenças dos resultados são importantes para situar alguns critérios de demarcação entre ciência e não-ciência, bem como a forma como se chega nas conclusões e o tipo de explicação.

Parece consenso entre os filósofos da ciência que os objetivos gerais da ciência consistem na explicação de fenômenos e eventos, e na previsão. Ademais, a ciência se

\footnotetext{
${ }^{3}$ Lecture II, "What Pragmatism Means". JAMES, William. Pragmatism, a new name for some old ways of truth. Cambridge, USA: Harvard University Press, 1978.

${ }^{4}$ A primeira formulação da máxima pragmatista foi no ensaio How to make our ideias clear (1878). 
caracteriza por um método que lhe é peculiar, que permite a avaliação de evidências segundo o contexto relevante para compreender o explicado, dispõe de critérios para selecionar uma entre outras hipóteses, e promove a adequação das explicações propostas (a forma do enunciado). Por certo, a explicação científica possui uma generalidade não acidental que diz o porquê; ela acrescenta conhecimento sobre o mundo; utiliza a experiência de casos passados; possibilita o teste futuro; altera a experiência à medida em que desvela relações.

Para compreender a atividade científica é importante romper com estereótipos, lembrar que no tocante ao interior da própria ciência, existem críticas acerca da sua rigidez, dificilmente aqueles que pensam seriamente sobre ciência se apegam a ingenuidade da neutralidade. Veja-se, por exemplo, a ideia de que o conhecimento científico merece crédito porque constitui um conhecimento provado, baseado em evidências: esta ideia provém da visão de que a ciência se baseia em premissas básicas auto evidentes e necessárias, fazendo parte de uma tradição que tem a geometria euclidiana como paradigma, e que, com o advento das geometrias não euclidianas, já não se sustentam. Como afirma Leônidas Hegenberg,"ela [a ciência] não é um edifício de pedra, assentado em pedra; é, antes, um edifício, de pedra talvez, mas assentado em lama e areia" (HEGENBERG, 1969, p.10). Nesta perspectiva segundo o critério de prova, não haveria nenhum conhecimento genuinamente científico, pois todo conhecimento do mundo é falível, contudo, ainda que seja passível de correções, o conteúdo da ciência não é um fluxo instável de opiniões e o mérito da ciência está no tipo de explicação que ela dá.

Conquanto haja a possibilidade de reprodução dos resultados, o método científico é mais do que uma aplicabilidade geral que comporta-se como receita, diferentemente o papel da imaginação no contexto de descoberta fora demasiadamente na literatura sobre o tema, não foi por acaso que Peirce (2008) afirmou que o raciocínio deveria ser feito de olhos abertos, tal metáfora reafirma a atitude crítica necessária a ciência. É certo que o método científico não é um conjunto de regras fixas que se devidamente seguidas levam a um resultado ótimo. Rubem Alves (1981) lembra um caso da história da ciência que além de ilustrar o equívoco da chamada observação pura, onde os fatos parecem orientar a teoria, serve-nos também para vislumbrar o método científico:

Tycho Brahe foi um grande astrônomo, contemporâneo de Kepler. Observador metódico, meticuloso, incansável. Registrou com rigor os movimentos e as posições dos astros e fez tabelas de suas observações. Entretanto, nunca chegou a formular a hipótese da centralidade do Sol. Kepler, que tinha sérias limitações como observador - vista muito ruim tinha a vantagem de uma imaginação fértil. Ganhava mesmo um pouco de dinheiro como astrólogo. Sua mente inquieta o levou a fazer as perguntas 
que o levaram à descoberta das três leis, perguntas que foram respondidas afirmativamente pelos dados coletados por Brahe. (ALVES, 1981, p.71)

Utilizando a metáfora de Peirce, parece que Kepler manteve os olhos abertos quando deu um salto qualitativo em relação ao trabalho de Brahe. Já os relativistas radicais, por sua vez, parecem utilizar um espantalho, quando fazem críticas à ciência: reclamam da autoridade, da pretensão, lançam argumentos vociferantes que acabam por equalizar ciência e senso comum. Ora, este ponto de vista confunde as particularidades de cada um desses empreendimentos cognitivos, enquanto esquiva-se das diferenças de procedimentos, não se trata apenas de soluções para problemas colocados pelo mundo, pois a natureza das soluções diferem. Os enunciados científicos podem ser testados, reproduzidos e generalizados independentemente de fatores culturais (espaço e tempo), ao passo que o senso comum (bom senso) está relacionado a uma cosmologia ${ }^{5}$ que varia de cultura para cultura, e satisfaz a condição de cumprir um papel dentro de um universo social.

Vale considerar, agora, um dos principais alvos dos relativistas radicais: a objetividade. O físico e filósofo da ciência Osvaldo Pessoa Jr. toma a objetividade (PESSOA, 2013) como a invariância de um resultado diante da mudança de observador, ou seja, a despeito da cultura ou do período histórico, uma teoria seria considerada objetiva à medida que seus resultados se mantivessem, sendo que a objetividade, nestes termos, consistiria em algo mais do que o consenso da comunidade, levando em conta as possibilidades futuras, bem como as histórias causalmente possíveis da ciência. Além disso, o critério de objetividade abarca, segundo Pessoa Jr., qualquer ser percepiente (extrahumano), isto é, vale para todos e está em consonância, sobretudo, com o caráter intersubjetivista da ciência.

Assim, destaca-se que

"a objetividade científica não é o resultado da atividade de um sujeito impessoal, mero executor de procedimentos eficazes por si mesmos, mas a conquista de investigações que, embora instrumentalizadas, nunca deixam de ser de algum modo "pessoais"'" (CUPANI, 1989, p.24)

A objetividade da ciência revisada pela filosofia refere-se a normas de procedimentos, assim como depende da ética científica, então, frequentemente, distingue-se o que seria a ciência ideal e a prática científica. Nesta perspectiva, a filósofa contemporânea

\footnotetext{
${ }^{5}$ Cosmologia consiste na própria visão de mundo, isto é na forma como o conhecimento é organizado e expresso; compreende a opinião geral, a totalidade do pensamento, que influi no sujeito que está inserido em determinada cultura que o socializa.
} 
Susan Haack chega a chamar de pseudo- investigações àquelas que são orientadas sem o princípio de honestidade e integridade da pesquisa ${ }^{6}$. Por último, é importante ter em vista que a pretensa objetividade os relativistas criticam não é sinônimo de neutralidade ou garantidora da Verdade, por isso, buscou-se a breve discussão sobre este critério tão complexo neste texto.

Em suma, compreender os elementos que tornam a ciência distinta de outras formas de conhecimento é a tarefa fundamental para a sociedade ocidental contemporânea, quando a influência da ciência aplicada, a abrangência dos enunciados científicos e as interações da comunidade científica estão presente no dia a dia, ainda que não seja percebida.

\section{A máxima pragmática de C. S. Peirce}

Conquanto Peirce não tenha feito uso do termo pragmatismo em Como tornar nossas ideias claras [How to make our ideas clear], publicado em 1878 em uma revista de divulgação científica/filosófica denominada Popular Science Monthly, sabe-se que esse ensaio constitui o primeiro escrito em que sua posição filosófica foi enunciada. De início é importante ter em vista que os estados mentais de crença e de dúvida desempenham um papel importante para a teoria do conhecimento peirciana (PEIRCE, 2008), pois as crenças determinam as ações práticas e acabam por gerar hábitos - delimitando o que se acredita ser verdadeiro. Por outro lado, a dúvida é um estado de desconforto que provoca o desejo de encerrá-la, sendo responsável pelos esforços despendidos para o estabelecimento de crenças que satisfaçam a inquietação da dúvida. Em outras palavras, ao adotar-se uma crença ela aplaca a irritação da dúvida todavia esse resultado não é infalível e eterno, mas, antes, parece um lugar de passagem que está em estreita relação com o futuro. Com o intuito de ilustrar esse ponto, Peirce (2008) utiliza uma metáfora sobre as notas musicais e as melodias: o pensamento é a linha melódica, e a crença fixada conclui a sinfonia intelectual até que seja excitada novamente pela dúvida. O filósofo afirma que isso ocorre porque:

[...] a crença é uma regra de ação; cuja aplicação implica dúvidas adicionais e pensamentos adicionais, então é, ao mesmo tempo, um lugar de chegada e também uma nova largada para o pensamento. $\mathrm{O}$ resultado final do pensar é o exercício da volição; e tal exercício já não faz parte do pensamento. Mas a crença é apenas um estágio da

\footnotetext{
${ }^{6}$ Susa Haack é uma filósofa que tem investigado temas de lógica, epistemologia e filosofia da ciência, atualmente ela é professora da University of Miami e possui uma formação influenciada pelo pensamento pragmatista, sobretudo, Peirce. É recorrente em sua obra a discussão sobre honestidade intelectual, integridade de pesquisa, racionalidade, objetividade, aqui, optou-se pelo ensaio traduzido pela plataforma Crítica na rede. Disponível em: http://criticanarede.com/filos_esperaresposta.html. Acesso em: 07 de dezembro de 2016.
} 
ação mental, um efeito do pensamento sobre nossa natureza. (PEIRCE, 2008, p.70)

No que diz respeito especificamente à teoria do conhecimento, Peirce criticava os métodos de investigação que substituem as dúvidas por crenças intuitivamente agradáveis à Razão dos filósofos. Para ele, os critérios usuais de clareza e distinção das ideias são insuficientes para a economia intelectual do bom raciocínio, no que decorre que o pragmatista buscou "formular um método de conseguir uma clareza ainda mais perfeita do pensamento" (PEIRCE, 2008, p.62). Para tanto, ele enuncia sua máxima pragmática, a saber: "Considere-se quais efeitos que concebivelmente teriam atuações práticas, os quais imaginamos que o objeto de nossa concepção possua. Então, nossa concepção desses efeitos é o todo de nossa concepção de objeto" (PEIRCE, 2008, p.73).

Peirce defende, na sequência, que a apreensão do significado dos conceitos filosóficos exige o esclarecimento deles em termos de seus efeitos práticos. Para tanto, ele fornece como exemplo uma análise pragmática sobre o conceito de realidade. Como os critérios de clareza e distinção são insuficientes, então é necessário agregar o terceiro critério, anteriormente mencionado, do exame dos efeitos tangíveis daquilo que chamamos de realidade. Segundo Peirce, no caso das investigações científicas, quando essas são levadas adiante o suficiente, diferentes investigadores deverão convergir em torno de uma mesma crença acerca do objeto de investigação, e é o objeto dessa crença o que ele denomina de real. Devem-se ter em conta, então, que o real existe independentemente dos pensamentos individuais, todavia possui relação com a opinião que está destinada a ser aceita por uma comunidade de investigadores em geral. Em suma, a verdade é concebida enquanto algo público, sendo que Peirce sustenta que o investigador deveria inquirir o que são os fatos tendo em vista que "[a] realidade do real depende do fato de que a investigação, se prolongada suficientemente, está destinada a finalmente levar a uma crença nela” (PEIRCE, 2008, p.85).

Como é evidente, Peirce fez uma defesa do método científico quando escreveu sobre as formas de aquisição de crenças (PEIRCE, 2008), resultado de seu trabalho durante anos em laboratório como pesquisador profissional, de modo que sua teoria está profundamente permeada pelo que John Dewey chamou de mente experimental ${ }^{7}$.

\section{O pragmatismo segundo William James}

\footnotetext{
${ }^{7}$ DEWEY, John. O desenvolvimento do pragmatismo americano.
} 
Há uma influência direta do pensamento de Peirce sobre William James, mas este último levou o pragmatismo a domínios até então fora do programa peirceano, fato que, décadas mais tarde, resultaria em discussões fervorosas sobre o que é, afinal, o pragmatismo. James costumeiramente citava com entusiasmo Peirce nos seus trabalhos; por exemplo, no Philosophical conceptions and practical results (1898), quando refere- $\mathrm{se}^{8}$ ao princípio pragmatista como um guia para compreender o significado da verdade e destaca o lugar do pensamento peirceano na filosofia:

Ele é um dos pensadores contemporâneo mais originais; e o princípio do praticalismo - ou pragmatismo, como ele chamou, quando eu o ouvi anunciá-lo em Cambridge nos primeiros anos de 1870 - é a pista ou bússola que pela qual sinto-me mais e mais seguro em acreditar que podemos prosseguir no caminho apropriado (JAMES, [1898]1992, p.1079).

James serve-se do que chamou de princípio de Peirce, no qual se a função do pensamento é a produção de crenças, sendo as crenças geradoras de hábitos de ação, então as consequências práticas do pensamento são os elementos essenciais que dão significado ao objeto ou ideia. Nesta perspectiva, o pensamento determina condutas e "para desenvolver o significado de um pensamento precisamos apenas determinar qual conduta ele adaptou para produzir: esta conduta é para nós o único significado" (JAMES, [1898]1992, p.1080).

Entretanto, ele particulariza os efeitos práticos significantes, de modo que os resultados sensíveis recaem sobre a experiência particular do futuro, portanto "o que a verdade significa de fato está na conduta que ela dita e inspira. Mas ela inspira tal conduta porque antecipa uma determinada volta à nossa experiência que exigirá de nós justamente essa conduta.” (JAMES, [1898]1992, p.1080). O princípio do pragmatismo, pois, encontra aplicação à medida que é possível fazer previsões; e este tipo de orientação revela a afinidade dos pragmatistas clássicos com o método científico. James chamou aos filósofos de pathfinders, ou seja, aqueles que indicam um lugar, o caminho da verdade, que pode ser buscado a partir da experiência e do intelecto humano. A verdade para ele constitui naquilo que funciona de maneira prática, em outras palavras, a verdade de uma ideia está em sua adequada relação com a experiência. Ele relaciona os pensamentos particulares com o universo de outras experiências para confrontá-los e verificar quais funcionam melhor.

Cabe lembrar o comentário de Cornelis de Waal no qual ele ressalta a diferença entre James e Peirce no que concerne ao significado da verdade:

"Enquanto Peirce almeja relacionar o significado de uma ideia com os

\footnotetext{
${ }^{8}$ James refere-se à série de artigos entre 1877-1878, onde Peirce expressa sua máxima pragmatista pela primeira vez na revista Popular Science Monthly.
} 
hábitos que a ideia ocasiona (que são gerais, não particulares). James relacionou o significado de uma ideia estritamente a particulares; isto é, sensações e reações" (WAAL, 2007, p.53).

Em 1907, James publicou um ensaio que consiste em uma reprodução da palestra que ocorreu na Universidade Columbia (1907) e no Lowell Institute (1906), parte de uma série que se propunha a tratar do pragmatismo e suas várias implicações para interpretação da realidade. Na segunda palestra, denominada What Pragmatism Means (1904) ele defende que para além de uma teoria geral sobre a verdade, o pragmatismo é também uma atitude investigativa que não busca resultados propriamente ditos, mas que pode ser usado para isso enquanto um método. Dessa forma, significado do nosso pensamento seria determinado pela conduta que ele produz e nossas crenças seriam orientadas para ação, no que decorre que ao examinar um problema filosófico do ponto de vista pragmatista, submetemo-lo ao princípio cujo qual as consequências concretas são levantadas, de sorte que se alcança a clareza a medida que os efeitos práticos são elucidados. Para James, conforme a II Lecture:

Não pode haver nenhuma diferença que não faça diferença - nenhuma diferença na verdade abstrata que não expresse uma diferença nos fatos concretos e na conduta consequente devido ao fato, imposto em alguém, de alguma forma, em algum lugar e em algum momento (James, [1907] 1978, p.30).

Uma das consequências filosóficas levantadas por James a partir desta consideração traduz-se do seguinte modo: dado dois posicionamentos filosóficos em disputa, supondo a verdade de cada um deles para examinar suas consequências práticas, se não houver diferença nos resultados, então temos um caso de diferença meramente verbal, em outras palavras, o problema está em como foram expressas (e não no conteúdo) suas soluções.

Com efeito, James utilizou o pragmatismo para examinar a controvérsia teísta, e isso importunou Peirce ao ponto de fazê-lo dedicar boa parte de seu tempo em refutar a James, muitas vezes de forma ácida. Vale observar, aqui, algumas razões que explicam o distanciamento dos desdobramentos de ambas as formulações do pragmatismo, por exemplo, a formação intelectual de ambos os filósofos. De um lado, James enquanto médico e psicólogo, com forte influência da biologia, baseado em uma visão de ciência mais nominalista ${ }^{9}$; de outro Peirce com uma trajetória orientada pelo pensamento físicomatemático, daí uma visão realista ${ }^{10}$.

\footnotetext{
9 “Por nominalismo, grosso modo, entende-se a tese de que os termos gerais são agrupamentos lingüísticos de instâncias particulares; portanto, quando a ciência fala, por exemplo, acerca de Massa (com M maiúsculo), na verdade agrupa-se sobre uma palavra propriedades que os corpos (com c minúsculo) apresentam. Por sinal, a idéia de tipo (espécime) ideal e da imutabilidade das espécies, no campo da biologia,estava em declínio depois da popularização de Darwin, que significava um avanço do nominalismo nas áreas biológicas. O nominalismo de James fez com que seu modo de olhar a ciência fosse mais relativizado, mas isso não quer dizer que James
} 
Pouco tempo depois, Peirce publicou What pragmatism is na revista The Monist como resposta às formulações do pragmatismo direcionado, sobretudo, para James, buscando recuperar o sentido original do pragmatismo até o ponto de rebatiza-lo como pragmaticismo, que nas suas palavras é um termo "feio o suficiente para ficar a salvo dos sequestradores" (PEIRCE, 1998, p.335). Peirce adota essa posição em nome do que ele chama de "ética da terminologia", pois defende que existe a necessidade de se estabelecer o uso filosófico comum, a fim de evitar confusões em relação a termos cunhados em circunstâncias delimitadas - tal qual o sistema taxonômico de Lineu na Biologia.

Desta feita, Peirce enfatiza o caráter experimentalista do pragmatismo na sua versão original, este caracteriza-se como jeito de pensar de laboratório, método de pensamento e verificação, onde dado uma hipótese científica, existe uma consequência experimental. O experimentalismo pode ser observado na consideração de que cada passo importante na ciência tem sido uma lição de lógica, em outras palavras, a história da ciência pode ser demonstrada através de seus resultados, o que revela o intuito do filósofo de estabelecer as fundações epistêmicas dos processos inferenciais. Nas palavras do filósofo:

Entre as coisas que o leitor, como uma pessoa racional, não pode duvidar, está que ele não tem meramente hábitos, mas também pode empregar uma medida de autocontrole sobre sua ação futura; o que não significa, entretanto, que ele pode transmitir qualquer caráter arbitrariamente conferido, mas, ao contrário, que o processo de auto preparação tenderá a transmitir a ação (quando a ocasião surgir) um caráter fixo, que é indicado e talvez grosseiramente medido pela ausência (ou invisibilidade) de sentimento de auto censura, que a subsequente reflexão induzirá. Agora, esta reflexão subsequente é parte de uma auto preparação para ação na próxima ocasião. (Peirce, [1905]1998, p.337)

Pode-se dizer que James possui uma visão mais psicologista da ciência que provém da noção de que a realidade pode ser ao mesmo tempo física e mental, este ponto de vista reflete o empirismo radical que concebe um mundo no qual ainda não aparecem nem sujeito nem objeto. Assim, enquanto que o experimentalismo está marcado na teoria peirceano, James se aproxima do instrumentalismo que constitui

uma tentativa de estabelecer uma teoria lógica precisa dos conceitos, dos juízos e das inferências em suas diversas formas, considerando primeiramente como o pensamento funciona na determinação experimental de suas consequências futuras. (DEWEY, 2007, p.236).

tivesse menos apreço pela ciência." (KINOUCHI, 2007:218) In: Notas introdutórias ao pragmatismo clássico. Sci. stud.,São Paulo, v. 5, n. 2, p. 215-226,jun.2007.

${ }^{10}$ Uma abordagem realista de ciência deseja explicar como as coisas são, sem abandonar a falibilidade das teorias científicas, por outro lado, o anti realismo não pretende descrever a realidade subjacente aos fenômenos. 
Finalmente, destaca-se a noção de ciência de James, expressa na sua principal obra The Principles of psychology (1890):

A ciência rende expressões que, dados os lugares e tempos, podem ser traduzidas em valores reais, ou interpretadas como porções definidas no interior do caos. Ela se torna um guia prático de nossas expectativas tanto quanto proporciona prazer teórico. Mas eu não vejo como alguém com senso dos fatos poderia chamar isso de resultados imediatos da experiência [tal como concebia Herbert Spencer]. Toda concepção científica é, antes de qualquer coisa, uma "variação espontânea" no cérebro de alguém. Para cada concepção que se prove útil e aplicável existem milhares de outras que perecem devido a sua falta de valor. Sua gênese é estritamente aparentada com aquelas inspirações poéticas, ou com as máximas de sabedoria, das quais as variações cerebrais também são a fonte. Mas enquanto a poesia e a sabedoria (como a ciência dos antigos) são sua própria razão de ser, e não vão muito além disso, as concepções científicas devem provar seu valor sendo verificáveis. Tal teste é a causa de sua preservação, não de sua produção (KINOUCHI, 2007, p. 2019 apud James, 1983, p. 1232-3).

\section{Conclusão}

A investigação sobre o pensamento pragmático permite a compreensão da ciência sem dar vazão a posicionamentos ingênuos. $O$ mérito do pensamento de James foi o reconhecimento que as circunstâncias que a vida impõe exigem, no mais das vezes, uma espécie de salto no escuro; nem todas as proposições são devidamente justificadas, nem mesmo as científicas, isso porque o intelecto é falível e a natureza volitiva do humano não pode ser deixada de lado, tampouco, isto seria possível durante a investigação científica. Este reconhecimento na teoria de James causou divergências com Peirce, sobretudo, porque James defendeu o direito à religiosa como algo razoável. Neste artigo não foram aprofundados os desdobramentos destas acepções, no entanto, o que é fundamental para os propósitos colocados é, justamente, o lugar que a ciência ocupa quando é retirada da torre de marfim.

Com efeito, as diferenças entre os filósofos não podem ser ignoradas. Peirce acreditava em um mundo onde as proposições científicas levadas suficientemente a investigação convergiriam para o mesmo ponto, fato que revela sua posição Metafísica, em outras palavras, se, para o filósofo, a verdade é algo público, após determinado tempo dedicado a investigação seria possível alcançá-la. Para James a verdade está estritamente relacionada aos efeitos sensíveis, ou seja, a verdade de uma ideia está na sua relação com a experiência. A despeito das diferenças entre o experimentalismo peirceano e 
instrumentalismo jamesiano, ambos articulam ideias notáveis sobre a ciência, fazendo usos distintos do método pragmático.

O pensamento de James, bem como o de Peirce, possibilita estabelecer critérios de demarcação da ciência que são frequentemente reiterados na literatura contemporânea de filosofia da ciência, assim, parece que o pragmatismo clássico teceu o mote da ciência de forma coerente em pleno século XIX, o que não é nada óbvio. Percebe-se que as teorias dos filósofos discute verificação, investigação científica,experimentação, falibilidade, tópicos que são de grande importância para a reflexão sobre ciência. Assim, a partir da herança pragmatista pode-se encarar a ciência do ponto de vista da justificação, a medida em que o chamado método científico é eleito como aquele que provém explicações satisfatórias, bem como em relação a atividade propriamente dita, pois não escapa aos filósofos o interesse movido pela investigação genuína.

É fato que o presente artigo não dialoga diretamente com o que tem sido os principais debates da filosofia da ciência atual, tampouco este era o objetivo. O que se espera com o presente texto, é introduzir o método pragmático como caminho possível para reflexão e compreensão sobre a ciência, ressaltando a possibilidade de considerá-la, principalmente, no seu caráter processual e intersubjetivo, sem contudo, abrir mão da ideia de que a ciência explica (ainda que provisoriamente). 


\section{Referências Bibliográficas}

ALVES, Rubem. Filosofia da Ciência - introdução ao jogo e suas regras. São Paulo: Brasiliense, 1981.

CHIBENI, Silvio Seno. Algumas observações sobre o "método científico". Notas de aula. 2006. Disponível em: <http://www. unicamp. br/ chibeni/textosdidaticos/metodocientifico.pdf> . Acesso em: 06 de março de 2017.

DEWEY, John. O desenvolvimento do pragmatismo americano. Cognitio-Estudos, v. 5 (2), p. 119-132, 2008.

HEGENBERG, Leônida. Explicações Científicas: introdução à filosofia da ciência. Ed. Herder/EDUSP, 1969, pp.13-24.

JAMES, William. Pragmatism: a new name for some old ways of truth. Cambridge, USA: Harvard University Press, 1978.

PEIRCE, Charles Sanders. Ilustrações da lógica da ciência. 2. ed. Aparecida, SP: Ideias \& Letras, 2008.

PESSOA JR, Osvaldo. A classificação das diferentes posições em filosofia da ciência. Cognitio-Estudos: revista eletrônica de filosofia. v. 6, n. 1, 2009. . Explorando a definição de objetividade a partir de histórias possíveis da ciência. 2013, p. 145-154. Disponível em: < $\underline{\text { http://www.fflch.usp.br/df/opessoa/Pessoa- }}$ Objetividade-Final-1.pdf>. Acesso em 15 de março de 2017.

KINOUCHI, Renato Rodrigues. A dinâmica da consciência: William James revisitado. São Bernardo do Campo: EdUFABC; 2015.

Notas introdutórias ao pragmatismo clássico. Sci. stud., São Paulo, v. 5, n. 2, p. 215-226, jun. 2007.

What pragmatism is. In: The Essencial Peirce: Selected Philosophical Writings, volume 2 (1893-1913). Bloomington: Indiana University Press, 1998.

RODRIGUES, Cassiano Terra. O desenvolvimento do pragmatismo segundo Dewey. Cognitio-Estudos (PUC-SP. Online), v. 5, p. 10, 2008.

WAAL, Cornelis de. Sobre pragmatismo. São Paulo, SP: Loyola, 2007. 